\title{
Arqueología (imaginaria) de la memoria: investigación estética y del simbolismo de la diáspora africana en Colombia
}

\author{
(Imaginary) archaeology of memory: \\ an investigation into the aesthetics and symbolism \\ of the African diaspora in Colombia \\ Martha Luz Machado Caicedo* \\ Grupo de Estudios Afrocolombianos de la Universidad Nacional de Colombia, Colombia
}

DOI: $10.22380 / 2539472 X .1388$

\begin{abstract}
RESUMEN
Este es un ensayo sobre metodología y estética $y$, a la vez, una propuesta sobre la historia cultural -específicamente la religiosa- de dos poblaciones habitantes del Pacífico colombiano: los afrodescendientes y los indígenas emberá y wounaan, también conocidos como chocoes. La aproximación teórico-metodológica se da a través de lo que he llamado una arqueología (imaginaria) de la memoria, formulación que permite reconstruir la memoria estética de pueblos y naciones, en este caso, de las culturas africanas transportadas por la trata esclavista a Colombia. El terreno que se excavará es el arte escultórico de la gente chocó, vinculado al sistema religioso indígena del canto de jai y con manifiestas huellas africanas. Desde una perspectiva africanista, esta propuesta analítica incorpora al África en un contexto indígena latinoamericano.
\end{abstract}

Palabras clave: arqueología de la memoria, arte, costa pacífica, amerindios, afrodescendientes, culturas africanas, Colombia.

\begin{abstract}
This is an essay on methodology and aesthetics, as well as a proposal regarding the religious and cultural history of two populations living in the Pacific coast of Colombia: Afro-descendant and Amerindian peoples: the Emberá and the Wounaan, also known as the Chocó. The approach to this topic is laid down by way of what I call archaeology of memory: a methodological formulation that makes it possible to reconstruct the aesthetic memory of peoples and cultures. In this particular case it is applied to African cultures transported by the slave trade to Colombia. The field to be researched/ excavated is the sculptural art of the Chocó people, who are linked to an indigenous religious system with evident African traces: canto de jai. So, springing from an Africanist perspective, this proposal Africa in an indigenous Latin American context.
\end{abstract}

Keywords: archaeology of memory, art, Pacific coast, Amerindians, Afro-descendant, African cultures, Colombia. 


\section{Introducción ${ }^{1}$}

Los documentos religiosos son al mismo tiempo documentos históricos; [...] cada documento tiene un significado particular, que es parte inseparable de la cultura y del momento particular del cual se ha desgajado.

(Eliade 1996, 123)

En este ensayo, reflexionaremos sobre los retos metodológicos que implica indagar por la memoria de los pobladores ancestrales del litoral pacífico colombiano: los pueblos indígenas de la familia lingüística chocó que acogieron a una buena parte de la diáspora africana y su herencia.

Empecemos por reconocer sujetos, objetos y terreno de trabajo. Los pueblos originarios wounaan-noanamá, eperara-siapirara y emberá conforman la familia lingüística chocó y habitan en resguardos situados a lo largo de la costa del Pacífico colombiano. Los wounaan-noanamás (nonaam) ocupan el bajo y medio río San Juan y los eperara-siapirara viven al sur de Buenaventura (Pardo 1987). Por su parte, la gran nación emberá es muy extensa. Comprende las variables lingüísticas de tres pueblos distintos: emberá dóbida, emberá chamí y emberá katío, que viven en asentamientos dispersos en diversas regiones de Colombia. Los emberás dóbida (gente de río) habitan en los departamentos del Chocó —que concentra la mayor población (un 63\%) en las regiones del Alto y Bajo Baudó y Bojayá-, Risaralda y Caldas. Los emberás chamí (eyabida, gente de la montaña), que se encuentran en el departamento de Risaralda, han ocupado la cuenca alta del río San Juan desde la época de la Conquista (ACIR y Ministerio del Interior 2012, 24); también habitan los departamentos de Quindío, Caldas, Valle del Cauca, Antioquia y Caquetá. Los emberás katío (igualmente eyabida, gente de montaña) se ubican principalmente en el noroccidente de Antioquia, aunque además habitan los departamentos de Chocó, Córdoba, Caldas y Putumayo, y se extienden a territorios de Panamá y Ecuador (ONIC s.f.). Pese a las diferencias regionales, estos grupos étnicos mantienen una unidad sobre la concepción del mundo y su relación con el entorno; “por lo tanto puede hablarse de los emberá en general por encima de las particularidades regionales” (Ulloa 1992b, 91).

\footnotetext{
1 Este trabajo se benefició de la infraestructura de las colecciones científicas portuguesas (PRIC.pt), así como de la colección del Pacífico colombiano del Museo de Culturas del Mundo, Gotemburgo. A ellos, mi agradecimiento.
} 
A esas comunidades las aglutina la vida espiritual, que abarca todas las instancias de lo cotidiano, la concepción del mundo, el principio de la unidad esencial. Para ellas, las plantas, las cosas, los elementos, todo cuanto existe, conforman una unidad interrelacionada (Ulloa 1992a, 1992b). Los chocoes poseen un sistema espiritual-terapéutico: el canto de jai o canto de la noche. Se trata de un culto ancestral que invoca a los espíritus atávicos, denominados familiares, representados en esculturas de madera tallada, hechas para curar la enfermedad (Friedemann 1983; Reichel-Dolmatoff 1960, 125-126; Robinson y Bridgman 1969; Ulloa 1992b; Vasco 1985; Wassén 1935, 112).

Vecinas ancestrales de los chocoes son las comunidades afrodescendientes, que habitan en los denominados territorios colectivos de las comunidades negras (TCCN). Su presencia allí es el resultado de más de trescientos años de ocupación desde que la economía colonial organizó el litoral sobre la base de la empresa minera. En ese lugar los españoles y sus hijos, los criollos, introdujeron masivamente durante dos centenas de años gente africana esclavizada para extraer el oro de las minas (Colmenares 1984, 239; 1997; Palacios 1984, 305; Romero 1993, 10). Una vez en este entorno hostil y agreste, los africanos -y luego sus hijos - tuvieron que (re)inventar los medios de sustento (Friedemann 1969, 1984; Friedemann y Arocha 1986; Machado 1996, 61). Tejieron grandes lazos de parentesco y forjaron la familia extendida; de generación en generación, aferraron su ancestralidad a los 850 kilómetros que mide el litoral (Friedemann 1993, 102). Así, en una frágil línea entre ríos, montes, playas y manglares anudaron con una pluralidad de oficios y quehaceres el trayecto de sus vidas (Arocha 1999).

La cercanía de las poblaciones indígenas primero con los africanos y luego con sus descendientes es una característica que ha definido el paisaje cultural de la región desde los albores del siglo XVIII. Los indígenas quedaron sometidos a la política colonial, a los resguardos y a la reducción de poblados; muchos huyeron a lugares inaccesibles de la selva como una de sus tácticas de resistencia a la colonización (Hernández 1995, 58; Vargas 1993). Se constituyeron entonces dos espacios geográficos diferentes: por una parte, entables mineros y encomiendas, con jerarquizaciones sociales disímiles (esclavos/amos e indios/encomenderos) $\mathrm{y}$, por otra, los pueblos de indios.

El examen que planteo se enfoca en la institución de la esclavitud y la población esclavizada en el territorio de los pueblos indígenas, en la geografía cultural y en la empresa minera, que es el punto donde convergen africanos -y luego sus descendientes-, indios y las instituciones que los dominaron (Werner 2000). Necesitaría mucho más espacio del que dispongo en este ensayo para explicar el tema con amplitud; solo permítanme recordar que considero la minería y sus estancias (minas, entables, caseríos, rochelas, etc.) como lugares 
estratégicos donde confluyeron los conocimientos de los africanos y de las primeras generaciones de afrocolombianos, la sabiduría de los pueblos originarios y de sus descendientes y la experiencia conjunta (Cantor 2000; Jiménez 2004; Jurado 1990). En ese tejido, mi propuesta consiste en conjeturar sobre las prácticas cotidianas de ambos pueblos en ese sitio de incertidumbre y dominación, aunque lejos del control colonial.

La hipótesis de este trabajo se sustenta en el argumento de Henry Wassén (1940), quien advirtió las similitudes entre las esculturas chocoes y las tallas africanas y manifestó que estas podrían responder a las influencias que los negros - como se refiere a los africanos - traídos desde Angola ejercieron sobre los indígenas. La suposición del etnógrafo sueco se basa en que el sistema religioso de los pueblos bantúes se fundamenta en el culto a los ancestros, representados en esculturas antropomorfas de madera.

Por ahora, basta decir que, tanto en África subsahariana occidental y central - sitio de origen de los ancestros de los afrocolombianos-como en el $\mathrm{Pa}$ cífico colombiano, las tallas sagradas son símbolos religiosos. Están formadas por un conjunto de signos inalterables y claros: todas acarrean la figura de un ser humano hierático, solemne y desnudo que, en algunas tallas, lleva las manos posadas sobre el vientre y, en otras, sobre el regazo. Estas esculturas repiten un lenguaje vernáculo y, por lo tanto, simbólico (Machado 2011).

Aunque el científico sueco planteó una interesante faceta del contexto histórico social de los chocoes sobre su cultura material, su espiritualidad y la influencia de la diáspora africana, su novedosa tesis fue marginada. Si la hipótesis de Wassén se hubiera tenido en cuenta y el autor hubiese incluido en sus investigaciones a los afrodescendientes y la memoria de África en su diáspora, se habría llenado de sentido la búsqueda de elementos conectores entre el arte de ambos continentes y se habrían abierto perspectivas de investigación. Mi propuesta busca encontrar precisamente eso.

Es bien cierto que el paralelo morfológico otorga información muy importante que ayuda a entender las memorias de los africanos, pero estos datos comparativos no son suficientes. Además, se corre el riesgo de que ese cotejo constriña la discusión a un enunciado en torno a "qué se parece a qué” y se dejen al margen las relaciones de esas (es)culturas con la religiosidad que las soporta y con la situación existencial que las hizo posibles. Por consiguiente, propongo indagar más allá e incluir en el análisis la situación cultural de dos poblaciones distintas, ubicadas en un tiempo y un espacio determinados, con el fin de perfilar vínculos y relaciones. Así, considero la escultura - que es la forma que toma lo sagrado - como un vehículo, un instrumento, para indagar los lazos entre África y América con base en las preguntas sobre la memoria religiosa y las 
formas que expresarían esa religiosidad en los pueblos y las naciones que conformaron la diáspora africana.

Hasta ahora no he encontrado etnografías o documentación histórica concerniente a la religiosidad de los africanos en el Pacífico colombiano en el comienzo de su historia en el país. Esta carencia es un tremendo problema metodológico que conlleva la necesidad de construir conocimiento sobre estas comunidades y sus descendientes en Colombia y que remite consecuentemente a África. Por ello, me lancé a atravesar los 10000 kilómetros de distancia que nos separan del continente africano e investigué sobre la espiritualidad en los sitios de origen de los ancestros de los afrocolombianos.

Mi proposición es interdisciplinaria y combina distintas áreas de conocimiento generalmente separadas: la historia del arte con la historia de las religiones, la semiología y la etnohistoria con el estudio de culturas distintas y distantes, y las relaciones interétnicas entre ambas poblaciones. Lo que pretendo hacer en este trabajo es ensamblar componentes a partir de un método comparativo, con un enfoque integral para la investigación sobre la diáspora africana que toma los siguientes ejes de análisis:

1. Argumentaré sobre la estética (las formas y técnicas y el rol simbólico) de las esculturas chocoes y africanas. Daré cuenta de las múltiples relaciones y las estructuras que las componen, así como de las similitudes halladas entre los dos continentes.

2. Referiré que las esculturas son símbolos insertos en los sistemas religiosos que las amparan y, como tales, están narradas en sus cosmogonías. El examen de los signos religiosos que aparecen en los mitos en ambos continentes y sus concomitancias es el segundo tema de este ensayo.

3. Como el estudio de los símbolos religiosos es el estudio de las personas (Cantwell 1996, 55), la historia cultural de la región — tanto la de los chocoes como la que debió resguardar la diáspora africana- atraviesa esta investigación.

4. Reconstruiré fragmentos de la historia religiosa de la diáspora africana en un ejercicio de anamnesis, a partir de signos y palabras que yacen en la espiritualidad de los chocoes, y en la de las naciones y los pueblos que surtieron las tropas de los esclavizados en el litoral pacífico.

5. En cuanto a la metodología, asumo una perspectiva africanista: al contemplar las esculturas como símbolos, las registré como dato histórico. En esto sigo la propuesta de Eliade $(1996,123)$ al referirse a los signos religiosos. De ahí que estas obras puedan dar cuenta de las memorias africanas en su exilio. 


\section{La estética de los ancestros (africanos) y de los familiares (chocoes)}

Antes de comenzar mi argumentación sobre la estética, quiero destacar la importancia de la denominación misma de las esculturas porque instala una relación entre espiritualidad y representación en los dos continentes: para los africanos, las estatuas vinculadas al linaje y a los antepasados son los ancestros, y para los chocoes, los familiares.

Figura 1. Bastones chocó, Colombia

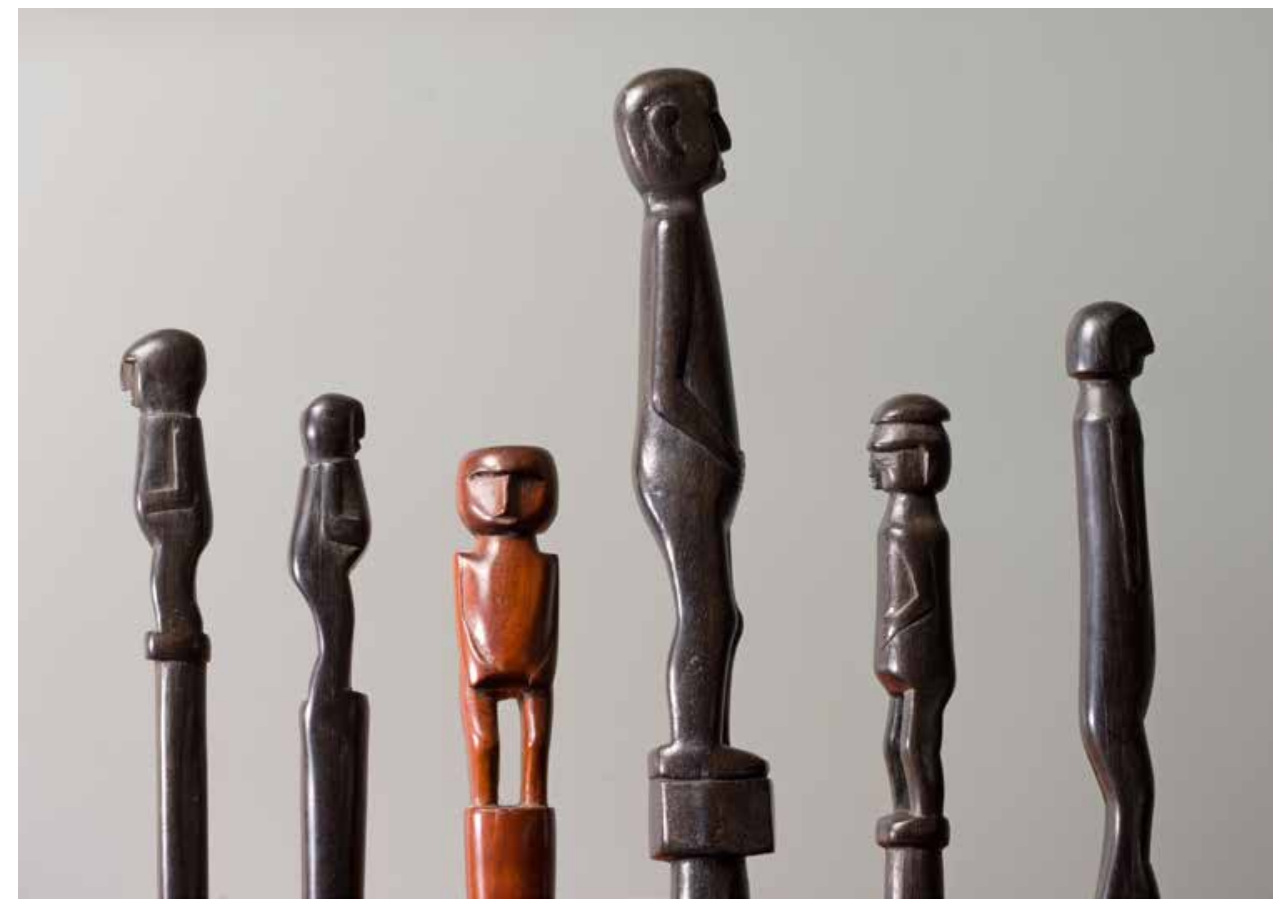

Fuente: colección de la autora, fotografía de Reindert Groot.

De igual modo, hay que tener en cuenta el gesto sagrado. Se trata de un patrón estético “sobrio" que, según Bastin (1961, 1982, 1986), es una pauta para representar al ancestro: hombre o mujer, en posición vertical, con las piernas flexionadas, los brazos atados al tronco y las manos sobre el estómago o sobre el regazo. Redinha (1962) define esta posición como un "código cultural o código anímico” (54). Este modelo general caracteriza las esculturas de culto en África y se repite en las esculturas chocoes. 
Figura 2. Bastón chocó

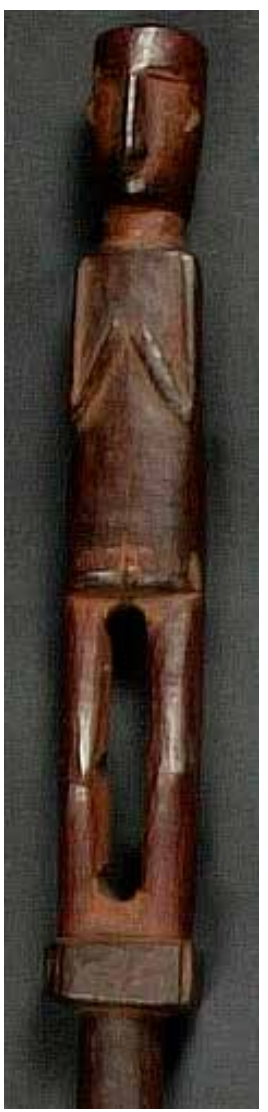

Fuente: colección Museo de las Culturas del Mundo, Gotemburgo, Suecia, 1927, registro 27.0495.
Figura 3. Bastón cokwe, Angola

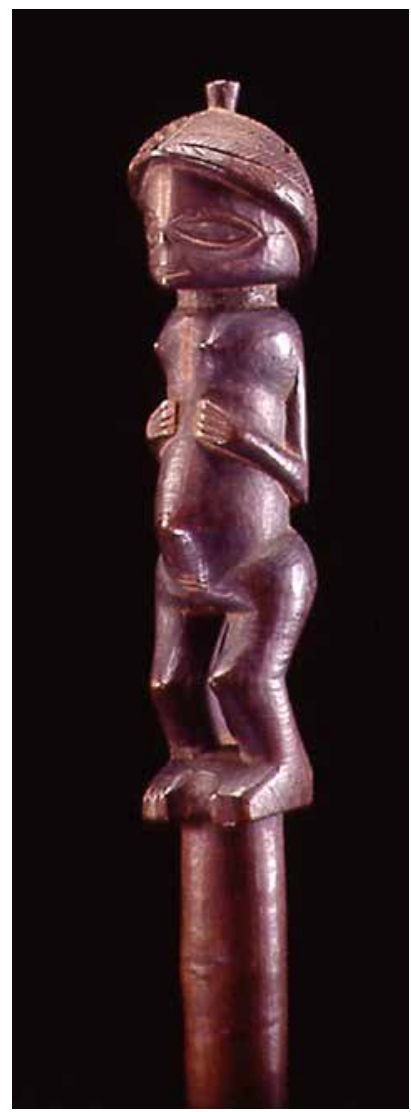

Fuente: colección Museo de la Ciencia, Universidad de Coimbra (MCUC), registro ANT.Ang.1.679\%.

Las conclusiones sobre la estética de la escultura chocó resultan del minucioso proceso de recolección, dibujo, examen y análisis de cada una de las 141 piezas que contiene la muestra que construí para la investigación. Mi trabajo en el Museo de las Culturas del Mundo de Gotemburgo, en el Museo de Antropología de la Universidad de Antioquia, en la colección del Museo del Oro de Bogotá y en las colecciones privadas a las que tuve acceso se convirtió en una caudalosa fuente de información sobre el arte de los chocoes, además de pautar y orientar la investigación.

Con el propósito de definir la forma estética de la escultura antropomorfa del pueblo chocó, elaboré un método etnomorfológico de análisis basado en el trabajo de Perrois (1966) sobre la estatuaria angolana. Este método me permitió comparar piezas del mismo grupo étnico, detectar conjuntos de discontinuidades 
y examinar los elementos fundamentales en la estatuaria. El ejercicio técnico consistió en calcular las proporciones de los componentes morfológicos (cabeza, cuello, tronco, extremidades, etc.) con respecto a la altura total de la pieza. Esto me llevó a crear un modelo (o modelos) de los estilos teóricos para precisar los signos semejantes que existen entre las esculturas de la muestra. Luego procedí a definir los estilos con base en la noción de Mills (1971), como un patrón estético que se extrae de un trabajo artístico: una regularidad, una repetición de signos durante un tiempo y espacio determinados. Partiendo de ahí, concluí que la escultura chocó es un documento fidedigno, símbolo de la manifestación religiosa y, como tal, guardiana de códigos fijos (posiciones y gestos rituales) que se mantienen inmutables en tiempo y espacio, y cuya estructura fundamental no se ha modificado en el periodo de cien años que abarca la muestra estudiada (Machado 2011, 248-249).

Figura 4. Bastón chocó, análisis de proporciones de cabeza y piernas

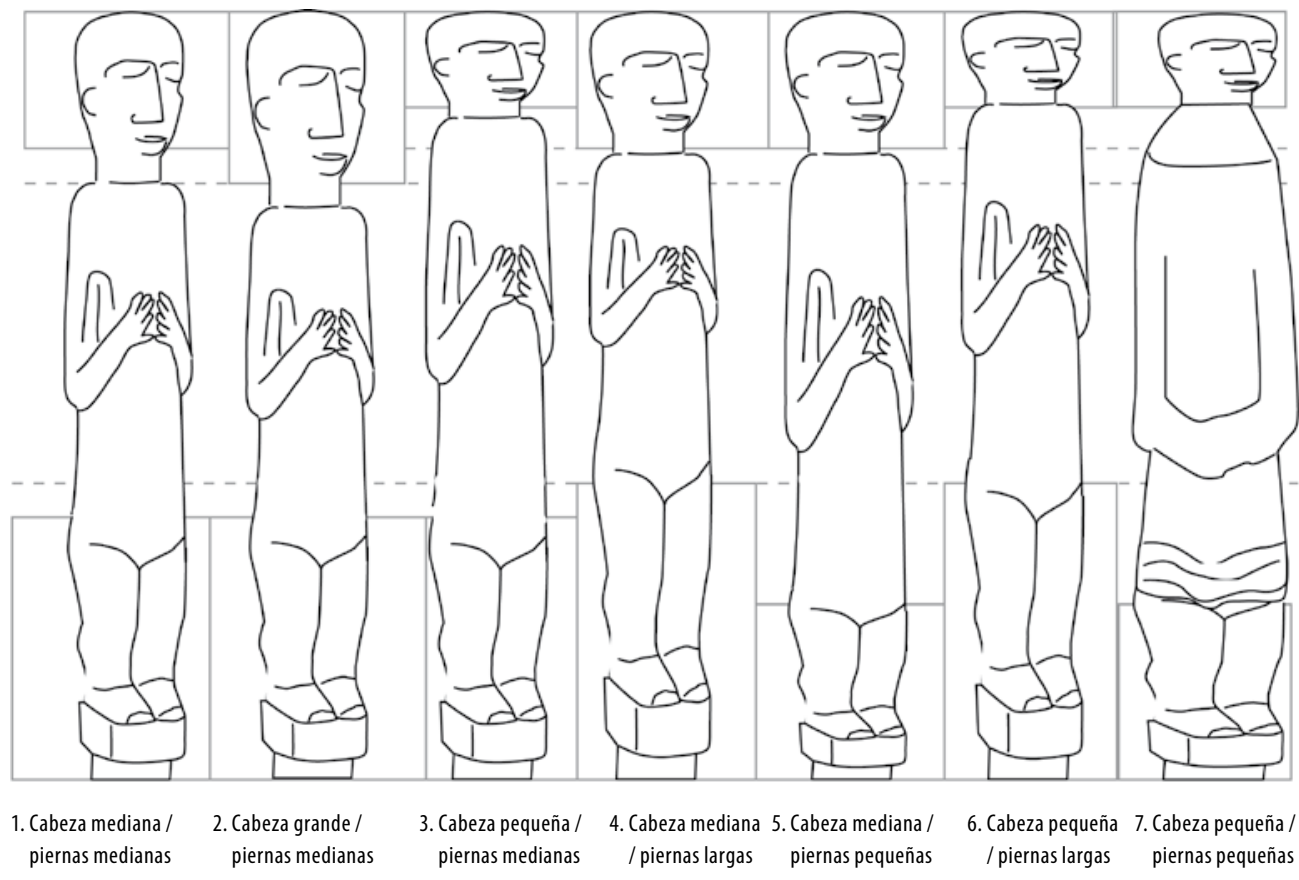

Fuente: elaboración propia. 
Otro aspecto metodológico que debo mencionar es que la forma de lo sagrado en África da razones para imaginar el legado estético de su diáspora. Esta idea me sirvió para delimitar el campo de estudio de la estatuaria en dos sentidos. En primera instancia, seleccioné el lugar geográfico en África de acuerdo con las poblaciones esclavizadas que fueron enviadas a Colombia, con el fin de lograr una caracterización que me permitiera relacionar región, estética y religiosidad. Metodológicamente, la identificación de las naciones involucradas en el comercio trasatlántico generó preguntas interesantes sobre la verificación de procedencia, no solo por la magnitud de la muestra — son trescientos años de trata esclavista y cientos de pueblos involucrados originarios de África Central y Occidental—, sino también por la diversidad de estilos y diseños que resguardaban estas poblaciones. En esta gran extensión espacio-temporal, investigaciones sobre el comercio de esclavos, como las de Eltis y Richardson (1997, 2010), Kloster (1998), Vila Villar (1977), Del Castillo (1981); bases de datos, como Slave Voyages: The Trans-Atlantic Slave Trade Database (Emory University 2019); y estudios equivalentes desde una perspectiva africanista, como los de Lovejoy (2012), Maya (1998), Miller (1988) y Thornton (1998), conformaron el puntal de mi investigación. Para dar un ejemplo de la complejidad de esta delimitación, tomo el antiguo Zaire ("río que traga todos los ríos”), hoy conocido como República Democrática del Congo. Esta región cuenta con más de un centenar de grupos étnicos y todos ellos ostentan diferentes estilos en su arte escultórico (Felix 1987). Según los datos de la etnografía de la trata esclavista, a estas personas se les catalogó como congos y angolas.

En segunda instancia, me limité a las esculturas de culto para identificar lo que podría ser la estética de los ancestros de los afrocolombianos y su legado. Así, tomé aquellas figuras que representan a los ancestros y que, según Bastin (1982), tienen forma humana y están desprovistas de accesorios; estas se conocen con el nombre de kampoya-tumpoya (plural) y rememoran un espíritu tutelar - hamba entre los bantú de África Central y bochio/boccio/bocie entre los ewe y fon de África Occidental—. En esa etapa de la investigación, la colección africana del Museo de la Ciencia de la Universidad de Coimbra y los documentos coloniales angolanos consignados en la biblioteca de esa universidad fueron un valioso germen. A ello se sumaron monografías y artículos sobre el arte de las poblaciones de estudio, entre los que destaco los de Lavachery (1954), Lamp (1996), Laude (1973) y Olbrechts (1959). En la misma corriente metodológica figuran los trabajos de Baeke (1996), Bourgeois (1984), Foss (2004), Bastin (1961, 1982, 1986), Neyt (1977), Perrois (1966, 1977), Phillips (1999) y Redinha (1962). Esta documentación se caracteriza por presentar una amplia perspectiva de cada una de las culturas africanas que estudia, pues, además de sus aspectos religiosos y etnohistóricos, incluye el análisis estético de las esculturas. 
Figura 5. Bastón con representación espíritu de difunto. Ovinbundo, Angola

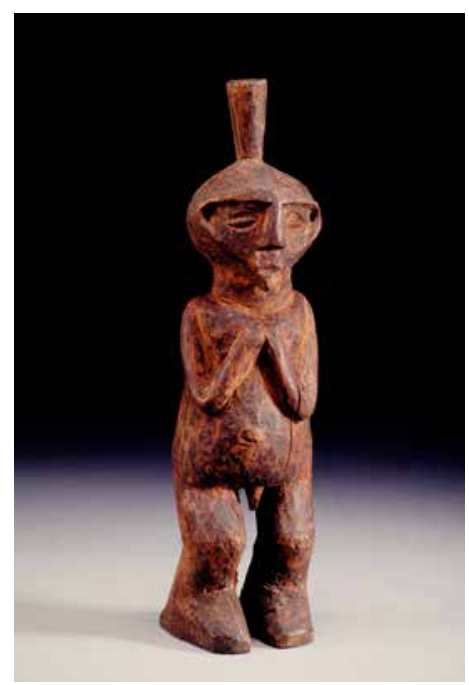

Fuente: colección Museo de la Ciencia, Universidad de Coimbra (MCUC), registro ANT.D.84.1.806.

Una vez determinado el análisis estilístico de la estatuaria chocó y de los diferentes grupos étnicos africanos, realicé una tarea fundamental: investigar, analizar y comparar dos conjuntos de datos extensos y ordenados, el primero de los cuales estaba compuesto por una muestra de esculturas chocoes y el segundo, por un corpus procedente de los sitios de donde fueron sacados los cautivos en África. Levanté los dos conjuntos en tiempos y lugares distintos. Los resultados arrojaron numerosas y complejas analogías que me llevaron a considerar otro objeto: el bastón cefalomorfo, que soporta un sistema de relaciones (morfológicas, artísticas, simbólicas y semánticas) asociado a contenidos históricos, culturales y espirituales muy profundos. Deduje que es una estructura y que es posible aislar sus componentes; el argumento más relevante tiene su cimiento en que estas esculturas son símbolos y, como tales, tienen una historia específica e íntima.

El estudio comparativo de las esculturas chocoes y las africanas me mostró que en ambos continentes se trata de figuras hieráticas con gestos rituales análogos que resguardan el código anímico ya explicado. Concluí que, aunque la colección chocó presenta en general una homología de estilo, contiene piezas que rebasan esa uniformidad. Estas figuras particulares generaron interrogantes y alteraron metodológicamente la información asumida sobre toda la colección y sobre la estética. El nuevo dato demandó examinar el repertorio de piezas como un sistema relacionado, pues al fin y al cabo el referente es la escultura chocó.

Esa noticia me permitió deducir la interacción que existe entre el dato estilístico, diferentes grupos culturales africanos y la etnografía de la trata en 
Colombia. Es decir, amplió mi campo de exploración y me devolvió a la pregunta sobre la existencia de este género único de escultura en Colombia. Derivé que es el resultado de la presencia en el país de diversos pueblos africanos con estéticas disímiles (Machado 2013). Esos datos singulares me llevaron a diferenciar el gentilicio dominante africano para incluir en el repertorio la singularidad de sus pueblos y de las culturas donadoras de su estética.

Al examinar esas piezas sui generis en la colección chocó, descubrí similitudes estéticas con África Central y Occidental. Los bastones cefalomorfos hacen parte de ellas. Se comparan muy bien con el poste figurativo con acento cefálico referido por Redinha (1962), que se encuentra en los pueblos quimbundo, lunda, gangela, bundas de Angola y otros grupos de África Central (53-55). Pineda y Gutiérrez (1984-1985), en su etnografía chocó, definieron estas macanitas como el habitáculo de los jaibanás desaparecidos.

Otra similitud apareció en una escultura antropomorfa compuesta por dos efigies en posiciones idénticas: las dos figuras están ligadas por los dorsos, comparten una porción de la parte posterior de la cabeza y, unidas, miran en direcciones opuestas. El examen comparativo etnomorfológico de las tallas de madera del África Central y el pueblo chocó me enseñó que la figura bifronte (Jano) es también una forma particular dentro de la estética de los bastones sagrados del Pacífico colombiano y que probablemente se puede plantear como un claro rasgo de africanía, más concretamente, de una huella estética bantú. Un análisis más atento sobre este caso puede encontrarse en mi ensayo "Un rastro de África Central” (Machado 2007).

Lo mismo ocurre con la figura que los chocoes nombran como páchaidammeisa ("solo una pierna"), perfectamente comparable con aquella que simboliza a los mellizos míticos del África Occidental. Allí, en Nigeria y al norte de Camerún, la gente chamba cuenta con mangki mesë - llamo la atención sobre la homofonía de la denominación de ambas figuras-, escultura que representa a un par de siameses. La figura está tallada en una pieza entera de madera que representa a un hombre y una mujer, unidos por la cadera, cada uno de ellos con una sola pierna. Sustentada en un complejo sistema religioso y en la tradición oral, esta talla personifica a los gemelos míticos de la asociación secreta Wangkya, ancestros fundadores de la sociedad religiosa terapéutica Rö (Baeke 1996; Machado 2011). Otra concomitancia es que las tallas son animadas por los espíritus del agua que, como ocurre con los chocoes, son una pluralidad de entidades sintetizadas en un ser sobrenatural benéfico que vive enterrado a las afueras de las aldeas, en los lechos de los ríos, en los nacimientos de agua o escondidos en el monte (Anderson 2002; Baeke 1996). 
Figura 6. Escultura chocó páchaidammeisa ("solo una pierna")

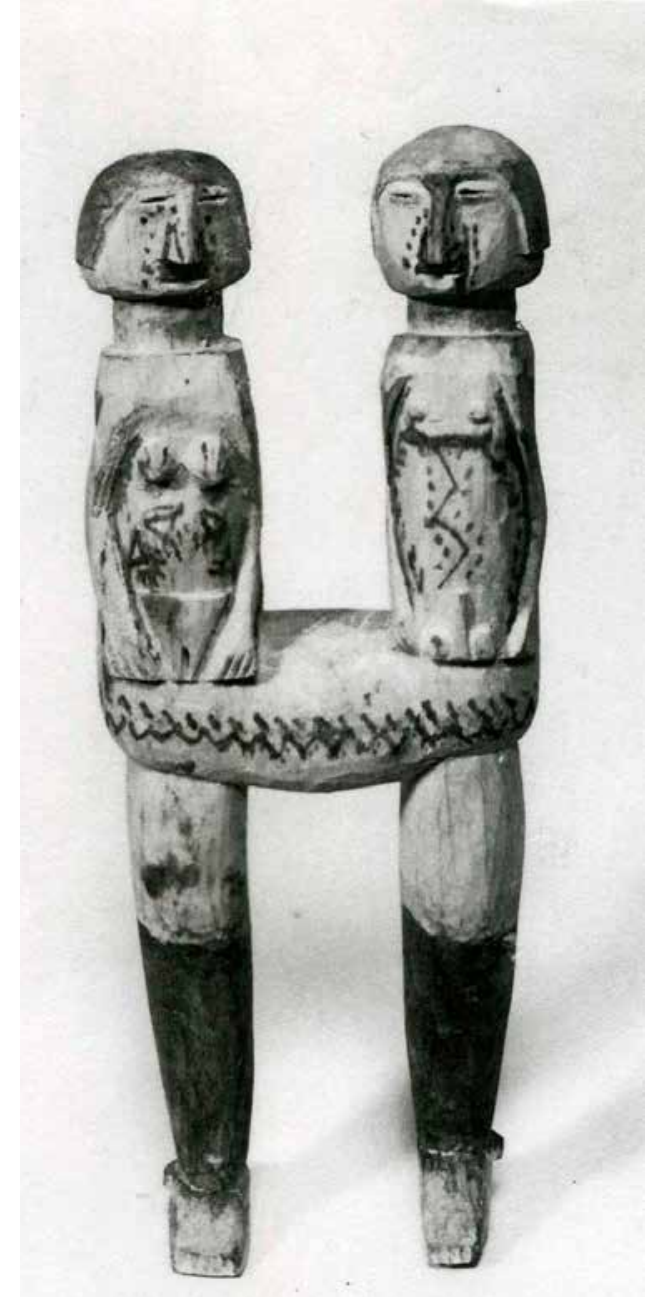

Fuente: Ccolección Museo de las Culturas del Mundo, Gotemburgo, Suecia, 1935, registro 14.22.
Figura 7. Escultura chamba mangkimesë

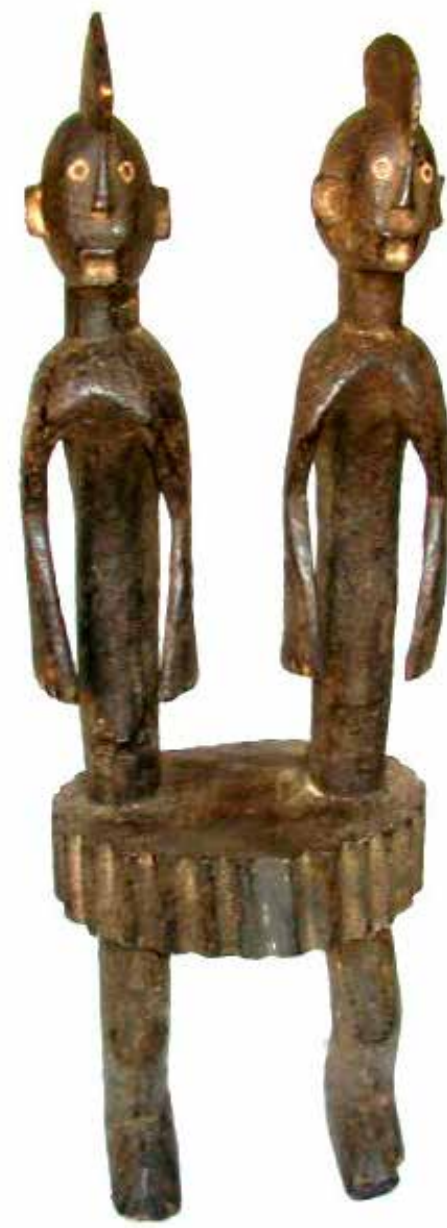

Fuente: colección Young Museum, San Francisco, California; fotografía de Wikimedia Commons, 2021.

Las tres figuras particulares otorgan una nueva información sobre la colección y sobre las personas que las elaboraron o que estuvieron en el espacio donde surgieron. Ahí es donde, como patrón cultural, la estética se convierte en un archivo de la memoria, porque ella, a través de sus rasgos, tiene la capacidad, la elocuencia fidedigna de informarnos sobre su propia historia, su origen y su devenir.

Si bien es cierto que las morfologías sirvieron para lanzar la hipótesis de la homología entre ambos continentes, las técnicas con las cuales fueron 
construidos estos objetos pueden reforzar las teorías arrojadas por el enfoque comparativo en el estudio de la cultura material. Sin embargo, al ser el bastón un elemento hierático, lleva en sí un dilema, una disyuntiva entre lo material y lo inmaterial, entre lo tangible y lo intangible. La comparación demanda indagar sobre una serie de actos y rituales, así como sobre las destrezas utilizadas por los talladores "tradicionales" del arte sagrado, tanto entre los chocoes colombianos como en las diferentes culturas africanas. Invita a analizar de qué modo se elabora, se produce, este arte (material).

El vocablo tradición está ligado a un sistema espiritual (intangible); por lo tanto, lleva en sí una regla invariable (el rito) con la cual tiene que ser construido, delineado, adornado y animado cada objeto deificado que se construye. Todos los sucesos en torno al objeto construido envuelven conocimientos ancestrales que remiten al ejercicio del hacer y que se trasmiten generacionalmente. Estas variables son útiles para revelar datos que requieren explicación, con base en la idea de que, en lugar de ser casuales, están ligados a una estructura mucho más compleja (la espiritualidad) en la que se deben incluir los hechos históricos y sus implicaciones. Un ejemplo es la pátina negra que caracteriza a los bastones tutelares tanto de los chocoes como de los africanos, porque devela conocimientos técnicos y sagrados. En ambos grupos, este color resulta de una destreza artística -involucra pigmento vegetal, agua, tierra y sangre de gallina- y de un conocimiento profundo del acto ritual destinado a la animación de las tallas y a conferir sacralidad.

\section{La cosmogonía: la palabra de los chocoes y los símbolos africanos}

Pese a la complejidad de la comparación, consideré que esos datos no eran suficientes porque estaba el riesgo de que la exploración acabara en un simple ejercicio de paralelos morfológicos — “qué se parece a qué”- entre las artes de los dos continentes. Entonces, retomé la conjetura de la forma de lo sagrado en África como posibilidad para perfilar la herencia estética de su diáspora (Machado 2011, 35); cambié el foco de examen y planteé la pregunta sobre qué es un bastón tutelar. Ello me llevó a examinar los estudios sobre el canto de jai, la institución religiosa que acoge el bastón. Después de analizar las etnografías escritas entre 1929 y 2006 (Friedemann 1983, 1989b, 1993; Losonczy 2006; Pardo 1987; Pineda y Gutiérrez 1958; Reichel-Dolmatoff 1960; Santa Teresa 1929; Vasco 1985; Wassén 
1935, 1988), concluí que el bastón es el habitáculo de los familiares: en él coexisten los espíritus de los antepasados de los chocoes. Consideré que este objeto es una de las elecciones estéticas del pueblo chocó para lo sagrado y, dado que está colmado de una realidad sobrenatural, es signo portador de significación religiosa; está ligado a un universo cosmogónico, religioso, espiritual y hierático muy complejo; es, además, un signo de poder (de poder hacer), de sabiduría; e inviste a los oficiantes, los destaca y los diferencia de sus congéneres (Machado 2011, 161-181).

Tuve que aprender que la unión entre arte, espíritus y ritual es indisoluble. Esto me obligó a realizar una documentación histórica y religiosa -en los términos que plantea Eliade (2009, 120-121) de integrar los datos sobre las religiones - del pueblo chocó y de los pueblos africanos, desde una perspectiva general y “como un hermeneuta”. De esta manera, mi investigación fue más allá para encontrar el valor religioso de los bastones: lo que Eliade $(1998,15)$ denomina hierofanía, lo sagrado.

Ahora bien, situar el bastón en el espacio de lo espiritual chocó me permitió analizarlo desde una categoría más extensa y, en consecuencia, abordarlo desde otras perspectivas. Una de ellas fue la cosmogonía que, según Eliade $(1998,59)$, contiene la respuesta sobre el origen de una realidad. Añade este autor que, cada vez que nace un símbolo o se repite un mito, se valida la reconstrucción de la memoria (12).

El repertorio de mitos que analicé empieza con la primera etnografía sobre los chocoes, realizada por el antropólogo sueco Erland Nordenskiöld en 1938, y concluye con mi entrevista a Zúñigo Chamarra, tallador de los familiares del pueblo indígena wounaan, en el 2006. Los mitos trascritos por etnógrafos y antropólogos (Arango 1993; Deluz 1975; Friedemann 1983; Friedemann y Arocha 1985; Hernández 1995; Nordenskiöld 1929, 1938; Pardo 1987; Pineda y Gutiérrez 1958, 1984-1985; Reichel-Dolmatoff 1953, 1960, 1961, 1962, 1988; Santa Teresa 1929; Vasco 1985; Wassén 1935, 1940, 1963, 1988; entre otros) narran los orígenes de las cosas; dan razón de los héroes culturales y sus proezas. Mi análisis se concentró substancialmente en los conceptos religiosos y su significado, en las formas narrativas, en el rol de los personajes que intervienen en el mito y en los rasgos característicos de cada actor. Las preguntas se centraron en los protagonistas de la historia: héroes, heroínas, seres sobrenaturales, entes zoomorfos, seres ambiguos, nociones todas muy complejas. La pregunta principal se sostuvo en la existencia de estos símbolos en el universo inconsciente, en este caso de los chocoes, que es el lugar en donde ocurre el mito según Eliade (1998, 1999).

Otro reto metodológico fueron los conceptos y las categorías. En efecto, frente a la multiplicidad de vocablos y mensajes que surgen en los mitos, parecía posible y útil definirlos, situarlos en un contexto histórico-cultural y delimitar 
cada uno por su significado. Así, interpreté los mitos de origen de los chocoes como una narrativa compuesta de varias imágenes que podían, por una parte, situar a los protagonistas en su realidad histórica y geográfica —en los términos de Eliade $(1974,12)$, en donde ocurren los sucesos de esa tradición-y, por otra, narrar la vida espiritual, los símbolos y los hechos religiosos que acontecieron en ese espacio desde el comienzo de la historia de dicha población.

\section{La religiosidad de los africanos y la anamnesis de su diáspora}

Las esculturas sagradas africanas tienen una genealogía milenaria —que se ha trasmitido y se sigue trasmitiendo de generación en generación-, una morfología inalterable —que se sitúa en el arkhaios africano (Picton 1995, 329)—, una historia y un soporte en la tradición oral. A través de un ejercicio de anamnesis historiográfica — método de recuperación del pasado, de una "ampliación vertiginosa del horizonte histórico”, propuesto por Eliade (2000, 108; 2006, 132)—, reconstruí fragmentos de la historia religiosa de la diáspora africana trayendo a la memoria las ideas y los hechos que han sido olvidados por los afrodescendientes. La tarea implicó retornar a África para buscar allí la existencia de esos datos (signos y palabras enigmáticas). Gracias a la memoria primordial, aquella que existe en la cosmogonía, pude recuperar la memoria originaria de la diáspora en Colombia y rastrear su continuidad en el inconsciente de los chocoes. Para llevar a cabo esta tarea, abordé desde múltiples perspectivas el entramado conformado por religiosidad, medicina y estéticas en el sistema religioso del culto a los ancestros. Concluí que estos elementos conforman una estructura en donde cada uno se relaciona con los demás (Machado 2011, 143).

Adicionalmente, indagué sobre la religiosidad de los africanos en una bibliografía muy extensa que abarca desde las crónicas del siglo XV hasta las más recientes investigaciones etnográficas. Para mí, ambas fuentes son imprescindibles; sin embargo, las crónicas de navegantes y misioneros portugueses fueron fundamentales porque describen la vida espiritual de los pueblos del África Central a comienzos de la irrupción portuguesa y en plena opulencia de la trata esclavista. Narraciones del siglo XVI, como las de los navegantes Duarte Lopes y Filippo Pigafeta (1951) y el misionero capuchino Giovanni Antonio Cavazzi (1965), contribuyeron a las discusiones sobre las estéticas de las esculturas de 
culto, pero sobre todo fueron una fuente valiosísima en cuanto evidencian aspectos fundamentales de la vida religiosa de los pueblos antiguos de África.

En ese momento de la investigación, la metodología de paralelos etnográficos propuesta por Eliade $(1996,35)$ me instigó a realizar una comparación entre los dos continentes. Los mitos de origen sobre la religiosidad africana completaron la exploración. Entendí que una cosa es describir los símbolos y los valores simbólicos de una cultura y otra es establecer relaciones entre varias y diferentes cosmogonías: la de los africanos del centro (los bantú) y del occidente (los ewe y los fon) cotejada con la cosmogonía de los chocoes. De ahí mi insistencia en que conocer la procedencia de las personas esclavizadas es inaplazable a la hora de identificar su espiritualidad. Considero que esos datos son las rutas y guías de este viaje y, por esto, me refiero a ellos antes de empezar a desentrañar las narrativas de los chocoes.

La interpretación de los toponímicos identitarios de los africanos en su exilio fue otro desafío de esta investigación. Consistió en establecer los distintos términos que hasta el momento había encontrado con los cuales se nombró a los africanos en el nuevo ámbito. Trabajos como el del lingüista Germán de Granda (1971, 1988) en los documentos de archivo sobre los esclavos del Chocó me permitieron observar la inmensa diversidad cultural africana en las minas de esta región (Machado 2011, 79-82). Si bien es cierto que la relación toponímica identitaria es un indicio para examinar las memorias de los africanos, porque ofrece información geográfica sobre el sitio de embarque (Maya 1998), no otorga datos concretos y suficientes sobre los cautivos, pues se refiere a un puerto en particular o a una gran extensión de tierra en donde habita un sinfín de culturas.

Por lo anterior, la reformulación de las claves de lectura amplía el horizonte de indagación sobre los africanos en su nuevo entorno. Por ejemplo, vocablos como angola, congo, loango, cabinda, vénguela, con los cuales se conoció en América a los africanos procedentes de África Central, invitan a reflexionar sobre el contexto histórico. Pero, ante todo, este repertorio que surge de la esclavización de los africanos, y como conveniencia del tráfico de esclavos, es un referente territorial que remite a la zona de captura, a los mercados y a los puertos de embarque (Mattos 2005, 153-154), al tiempo que despoja a los cautivos y cautivas de su identidad étnica.

Metodológicamente, la reinterpretación de ese escenario me obligó a abrir el espectro de investigación para incluir el análisis de la gente bantú que allí habitaba: bakongo, lunda-quioco (o cokwe), ovimbundo y mbundo, nganguela, entre otros grupos étnicos, descritos en crónicas coloniales como las del misionero capuchino João Antonio Cavazzi (1965). Para entender la complejidad de este asunto, alcanza decir que el término bantú refiere a cualquier individuo 
perteneciente a los más de cuatrocientos grupos étnicos de pueblos melanoafricanos que hablan lenguas bantúes y que viven al sur de una línea que va desde Duala (Camerún) hasta la desembocadura del Yuba (Somalia). Similar problema encontramos con la referencia ewe-fon, unión de dos vocablos que corresponden a una clasificación geográfica que compacta etnias distintas y territorialmente distantes.

De acuerdo con la población africana que abasteció el comercio esclavista y su situación geográfica, en su orden estarían los ewe, habitantes de Togo y Benín; los yorubas, de Benín y Nigeria; los igbos o ibios, de Nigeria y Camerún; y los fon, de Camerún. Con estos grupos llegaron también los ararás (aradas, asaras o aladas), designados con este nombre porque fueron sacados de Allada, la ciudad santa del reino de Dahomey; corresponden al grupo fon y, al igual que sus coterráneos, fueron embarcados en el golfo de Benín. Se trata de desbaratar el discurso esclavista que soporta estas categorías globales que han sido sólidamente afianzadas y entrelazadas con el concepto generalizado y homogeneizado de africanos. Esto obliga a incluir formas de investigación que permitan reconstruir memorias e identificar actos y actores frente a preguntas tales como: ¿cuáles fueron los conocimientos y memorias acarreados por este repertorio étnico?, ¿cuáles son los legados particulares de estas culturas, una vez puestas al otro lado del Atlántico?

Retornando a los paralelos etnográficos, encontré asombrosas similitudes entre Colombia y Benín (Machado 2012). El reto consistió en comprender los diferentes, complejos y multifacéticos fenómenos religiosos que estaba abordando. Aquí, el método interpretativo sobre el simbolismo propuesto por Eliade (1996, 116-139) fue muy útil a la hora de enfrentarme a un enjambre de datos anunciados por la cosmogonía de cada una de las culturas que estaba analizando: héroes, proezas, gestos, elementos profanos y sagrados, conceptos sobrenaturales complejos y sistemas religiosos, entre otros. Tales datos simbólicos designaron la presencia de un universo particular en cada sistema religioso, aun con el Atlántico de por medio.

Etnografías como las de Melville y Frances Herskovits (Herskovits 1938; Herskovits y Herskovits 1958) son primordiales; de sus trabajos rescato Dahomean narrative: a cross-cultural analysis (1958) porque reúne una extensa colección de las narrativas de la gente fon - ancestros de los afrocolombianos-, que me permitieron crear la conexión con África Occidental y mostrar las sobrevivencias y las trayectorias de los legados en Colombia. Por ejemplo, en términos de valores simbólicos, fue interesante observar la comparación y las concomitancias entre ambos continentes frente al concepto de medicina y la consecución de las curas, puesto que envuelven héroes, hierbas medicinales, entes naturales y 
lugares geográficos. Concretamente, el análisis comparativo sobre los héroes culturales es un buen modelo. Jerú Poto entre los chocoes y Tohuso en la mitología dahomeniana son personajes que poseen el don y el conocimiento de curación, así como las pócimas que curan; además, están dotados de poderes extraordinarios. Tanto el Jerú Poto colombiano como el Tohuso africano tuvieron una gran significación teórica porque me permitieron observar la persistencia de símbolos que han trascendido en el tiempo, de una generación a otra, en la vida de esas culturas.

En consonancia, en ambas cosmogonías se hace referencia a conceptos y categorías fundamentales que corresponden al mundo mítico de cada cultura. Estos personajes son cazadores, mellizos, huérfanos, provienen de un nacimiento anormal —en una y otra cosmogonía, son “el hijo de la pierna”-, tienen el don de la palabra desde su nacimiento y están protegidos por los espíritus del agua, de donde emana su poder. Las analogías entre el acto, las proezas y los símbolos persistentes me permitieron argumentar que los sistemas chocó y africano comparten una tradición oral parecida, que sitúa en planos comparables a entidades mitológicas que intervienen en el origen de los sistemas médicos, bajo el amparo de nociones y filosofías de las cosmogonías en las que emergen. Los personajes mencionados solo pueden pensarse dentro de la compleja estructura de los sistemas religiosos que los sustentan; un orden que contiene religiosidad, medicina, curación y esculturas (Machado 2011, 132).

Otro aspecto metodológico que debo referir es la escasez de palabras en idiomas africanos o de raíz africana en la cosmogonía chocó; sin embargo, existen conceptos, vocablos e ideas complejas del mundo espiritual, es decir, datos inmateriales que es posible relacionar con fundamentos y símbolos de la cosmogonía africana. Uno de estos casos es el concepto chocó de puercos de monte. Se trata de una entidad que vive en el mundo de abajo, aquel donde ocurre la curación y en el que existen las plantas medicinales. Encuentra correspondencia a través de su traducción literal al español en la cosmogonía de la gente bakongo, así como en los lugares donde se expandió su diáspora. Desde este punto de vista, trabajos realizados por lingüistas y antropólogos sobre África y la diáspora africana proporcionan un campo promisorio para la investigación. Para ilustrar este ejemplo, resalto el estudio de Fuentes y Schwegler (2005) sobre el sistema afrocubano de creencias de sustrato lingüístico-cultural bantú conocido como regla de palo mayombe o regla conga, porque se refiere a los nombres de las entidades paleras y su procedencia etnolingüística africana. Se trata del culto a los ancestros en el cual un receptáculo sagrado, llamado prenda, contiene los palos investidos por la fuerza de los espíritus y de las entidades divinas; algunos de 
estos objetos tienen forma antropomorfa y representan al ancestro. Presumen dichos autores que los elementos africanos encontrados en el léxico de este ritual pueden ser rastreados hasta su origen kikongo ${ }^{2}$ porque, además, la investigación proporciona datos puntuales sobre su etimología y sus significados.

Así fue como, navegando en este complejo y extenso repertorio, pude discernir el significado de la noción puercos de monte, concordante con la palabra africana ngulumfinda que, según Fuentes y Schwegler (2005), es la acepción que utilizan los bakongo (parte de los bantúes) para nombrar a los sabios de las yerbas (189); una voz kikongo que significa “jabalí, cerdo salvaje”, que aparece entre los paleros cubanos como gurufinda (189). Mi deducción tiene su cimiento en el significado del concepto, allá en África Central, que se refiere al médico experto en las hierbas. Se trata de una metáfora, pues el oficiante -igual que el jabalí, tatabro o cerdo salvaje- se interna en el bosque para buscar plantas, raíces y bejucos que utiliza para preparar medicinas, amuletos y pócimas.

De igual manera, concluí que esa imagen comparte los mismos principios fundamentales con África centromeridional y con Cuba; es un signo de origen bakongo. Si bien la palabra africana está ausente, sí existe en el léxico chocó un vocablo que representa esa noción. Esta interpretación me conectó en una línea de coordenadas con los yerberos africanos, con los cubanos y los colombianos. Además, la deducción desbordó mi asociación entre los chocoes, los africanos (bantúes) y su diáspora en Cuba, y trajo a la argumentación a los raiceros y yerberos afrodescendientes y chocoes — también conocidos como chinangos (Meza 2010) - del litoral pacífico colombiano. Deduje entonces que la imagen de puercos de monte es un concepto que pertenece al terreno mítico de los chocoes, que es comparable con Cuba y tiene su origen en las selvas de Mayombé angoleñas. Representa a los expertos en el manejo de las plantas, sus dones y virtudes; en cuanto símbolo, forma parte de una estructura religiosa que une al oficiante médico con la espiritualidad, las esculturas, la selva y las hierbas.

Con base en la idea de que los mitos son la biografía del grupo (Boas 1915, citado en Herskovits y Herskovits 1958, 7) y de que la tradición oral puede interpretarse como historia (Vansina 1985, 27), rebasé su observación como textos simbólicos para concebirlos como la memoria oral - una crónica- de los chocoes sobre sus tiempos primigenios. Uno de estos análisis lo conforma la tradición oral recopilada por Arango (1993) sobre el mito de origen de la medicina y la cura; ahí la memoria primordial de los chocoes da cuenta de las íntimas relaciones que sucedieron en el litoral entre estos dos pueblos. Así, las antiguas

2 Lengua bantú hablada por los habitantes de los bosques tropicales de República Democrática del Congo, República del Congo y Angola. 
tradiciones grabadas en los mitos de origen sobre el sistema médico-religioso me permitieron explicar cómo los africanos o sus hijos aparecen transmitiéndoles a los indígenas sus conocimientos religiosos y terapéuticos. Concluí que esos relatos dan cuenta de una cartografía móvil y completa que situó en el mismo territorio a indios y cautivos africanos, quienes aprendían unos de otros, se enamoraban y establecían formas de convivencia (Machado 2011, 91-115). Ahí aparecieron los africanos o sus hijos, sujetos de su propia historia, dueños de un saber que legaron (enseñaron) a los primeros jaibanás.

Los trabajos de historiadores y etnógrafos fueron una fuente indispensable y próspera para plantear estas conjeturas sobre las relaciones interétnicas en el litoral, así como sobre las trasferencias de conocimiento. Las investigaciones de Jiménez (2004) y Jurado (1990) sirvieron para explicar que las uniones entre indios y afrodescendientes - y sus ancestros - desbordan la idea de zambaje — concebido como una simple mezcla de razas - y constituyen genuinos intercambios culturales, producto de la reciprocidad y de las negociaciones cotidianas. Los trabajos de Arocha (1999), Losonczy (2006) y Ulloa (1992a) contribuyeron a destacar las alianzas y los intercambios en el ámbito sagrado entre ambos pueblos.

Huellas de africanía es el concepto desarrollado por Nina S. de Friedemann (1989a) que indica la presencia de rastros culturales africanos que se manifestaron en América como consecuencia de la trata, a partir del siglo XVII. Arocha (2002, 57; Arocha et al. 2008, 24) argumenta que tales africanías tienen diversas intensidades que contrastan entre la nitidez de algunas expresiones de africanidad y el desvanecimiento de otras. Con base en este argumento y con la certeza de la presencia de los africanos en esta historia, concluí que el pasado de los chocoes está también conformado por la diáspora africana y sus legados; ellos salvaguardaron y son el depósito de la reminiscencia religiosa de los africanos en su exilio al principio de su historia en Colombia. Esto es, los chocoes resguardan en su espiritualidad huellas de africanía.

\section{Conclusiones}

Con mi trabajo investigativo he ensamblado un cuerpo de la memoria de la diáspora africana compartida con los pueblos originarios chocoes. Está integrado por la memoria de los descendientes de los africanos, los referentes culturales de sus ancestros en África y la historia común de los indígenas del litoral pacífico. En otras palabras, se juntan discusiones interrelacionadas: memoria cultural, 
implicación religiosa, dimensión espaciotemporal y relaciones interétnicas. Ese cuerpo se manifiesta en la religiosidad, la estética y la tradición oral. Así, es posible pensar que la iconografía chocó es un depósito de la memoria estética de la diáspora africana. La evidencia tangible de las similitudes entre las esculturas sustenta la hipótesis de continuidad de la herencia cultural africana fuera de los límites de África - africanidades, en términos de Arocha (2002, 2008)—, esencias que no fueron destruidas por el horror del traslado forzado de la gente de ese continente al Pacífico colombiano.

Considero que he contribuido al desarrollo de diferentes áreas de los estudios africanistas/afroamericanistas; he aportado una metodología que puede ser útil a la solución de problemas relacionados con la historia de los africanos fuera de los límites de África. El reto epistemológico consistió en crear nuevos archivos: el de la escultura chocó y el de la memoria de los africanos. De allí surgió mi idea sobre la estética como un archivo que puede ser leído e interpretado. También surgió la propuesta de releer los mitos y la historia oral. Así aparecieron lecturas diferentes sobre la región, su gente y sus intercambios. Esta interpretación sitúa a África en el marco de la arqueología (imaginaria) de la memoria, propuesta metodológica que utilicé para indicar los fragmentos de las estéticas de los pueblos africanos y que puede proveer una contribución tangible al conocimiento sobre aquellos sujetos ausentes de los registros históricos, cuyos aportes culturales permanecen sin reconocimiento.

Estos fragmentos se pueden rastrear tanto en el sistema religioso del canto de jai de la gente chocó como en los sistemas religiosos de los grupos que conformaron las tropas de esclavizados originarios de África Central y Occidental. Se concretan en los códigos morfológicos y anímicos y en los patrones estéticos que resguardan las esculturas en ambos continentes. Así mismo, se localizan en la cosmogonía, en los mitos, en sus conceptos y vocablos; es decir, en documentación tangible e intangible que ha sido la fuente de mi indagación. La persistencia temporal y la inmutabilidad de símbolos, imágenes, vocablos y estéticas presentes en el sistema religioso chocó del canto de jai, así como la reiteración de mitos en su cosmogonía, y al ser comparables con similares caracteres africanos, constatan una continuidad de larga duración que considero como vestigios e indicios de la memoria de las personas africanas en Colombia, es decir, de las culturas legatarias de estas epistemologías.

Al estudiar vocablos, conceptos e ideas complejas del mundo espiritual, narrados en los mitos del canto de jai - es decir, al examinar los datos inmateriales que soportan la existencia de las esculturas-, no encontré palabras en idiomas africanos o de oriundez africana, como sucede en otros lugares en donde se expandió la diáspora. Sin embargo, desentrañé expresiones que representan 
conceptos fundamentales de las religiosidades y filosofías africanas. Podría especular entonces que, si bien los términos en idiomas africanos están ausentes en el lenguaje de los chocoes, sus nociones siguen existiendo en la traducción que se les ha dado. Este es el caso de conceptos y símbolos como familiares, espíritus del agua y puercos de monte, que denotan la presencia y la persistencia de la espiritualidad de los cautivos africanos en el Pacífico colombiano.

La arqueología imaginaria de la memoria permite responder interrogantes sobre las culturas y las naciones africanas transportadas por la trata esclavista a Colombia. Consiste en un método que intenta (re)construir el principio y el devenir de estas culturas; en el caso que nos ocupa, su vida religiosa en el Pacífico colombiano. Uso una derivación del verbo imaginar porque me refiero a sucesos de los cuales no tenemos certidumbre debido a la exigua información sobre esta comunidad y que es preciso excavar en un terreno ajeno o propio, pero que es potencial para la investigación. Sea como fuere, la relación geográfica entre Colombia y África me ha sido útil para describir el pasado religioso de los ancestros de los afrocolombianos, porque vincula a estos antiguos habitantes con los actuales en Colombia, en África y en donde se expandió su diáspora.

\section{Referencias}

\section{Fuentes primarias}

\section{Colecciones estudiadas}

\section{Colección Esperanza Casas, Bogotá, Colombia.}

Museo de Antropología de la Universidad de Antioquia, Medellín, Colombia. Colección Pacífico Colombiano.

Museo de la Ciencia de la Universidad de Coimbra, Coimbra, Portugal. Colección Angola África Central.

Museo de las Culturas del Mundo, Gotemburgo, Suecia. Colección Chocó y Cuna, Pacífico Colombiano.

Museo del Oro, Bogotá, Colombia. Colección Bastones Chocó. 


\section{Crónicas}

Cavazzi, João António. 1965. Descrição histórica dos três reinos do Congo, Matamba y Angola. Lisboa: Junta de Investigações do Ultramar.

Lopes, Duarte y Filippo Pigaffeta. 1951. Relação do reino do Congo e das terras circunvizinhas. Traducción de Rosa Campeans. Lisboa: Agencia General do Ultramar.

\section{Entrevistas}

Zúñigo Chamarra, pueblo indígena wounaan, Puerto Pizario, litoral del río San Juan. Entrevista realizada por Martha Luz Machado Caicedo. Cali, Colombia, 22 al 30 de febrero de 2006.

\section{Fuentes secundarias}

ACIR (Asociación de Cabildos Indígenas de Risaralda) y Ministerio del Interior. 2012. Plan salvaguarda de los emberás chamí del departamento de Risaralda. Pereira, Colombia: ACIR / Ministerio del Interior. Consultado el 17 de septiembre de 2020. http://www.mininterior.gov.co/sites/default/files/p.s_embera_chami_risaralda.pdf

Anderson, Martha. 2002. "Water spirits shrines”. En Ways of the river: art and environment of the Niger delta, editado por Martha G. Anderson y Philip M. Peek, 162-165. Los Ángeles: UCLA / Fowler Museum of Cultural History.

Arango Ruiz, Diego. 1993. “Quinientos años después... Testimonio de las comunidades indígenas y de la Organización Regional Embera Wuanana del Chocó”. En Colombia Pacífico, vol. 2, editado por Paulo Leyva, 777-787. Bogotá: Fondo para la Protección del Medio Ambiente José Celestino Mutis.

Arocha, Jaime. 1999. Ombligados de Ananse: hilos ancestrales y modernos en el Pacífico colombiano. Bogotá: Universidad Nacional de Colombia.

—. 2002. Africanía y globalización disidente en Bogotá. Bogotá: Universidad Nacional de Colombia.

Arocha, Jaime, Juliana Botero, Alejandro Camargo, Sofía González, Cristina Lleras, Dilia Robinson, Alfonso Cassiani, Carlos Andrés Meza, Óscar Almario, Mario Diego Romero, Zamira Díaz, Ramiro Delgado y Lina del Mar Moreno. 2008. "Velorios y santos vivos”. En Velorios y santos vivos, editado por el Museo Nacional de Colombia, 31-70. Bogotá: Museo Nacional de Colombia.

Baeke, Viviane. 1996. "Water spirits and witchcraft: rituals, myths and objects MfunteWuli, Western Camerun”. En Objects of Africa, editado por Luc de Heusch, 57-91. Bicariof: Musée Royal de l’Afrique Centrale.

Bastin, Marie-Louise. 1961. Art decoratif Tshokwe. Angola: Compahia de Diamantes de Angola (Diamang) / Subsídios pra História, Arqueologia e Etnografia dos Povos da Lunda.

—. 1982. La sculpture Tshokwe. Meudon: Alain et Françoise Chaffin Editeurs. 
—. 1986. “Art scultural de l’Afrique Bantu, Muntu”. Libreville 4-5: 137-163.

Boas, Franz. 1915. “Tsimshian mythology”. En Thirty-First Annual Report of the Bureau of American Ethnology 1909-1919, editado por Bureau of American Ethnology, 27-1037. Washington: Government Printing Office.

Bourgeois, Arthur P. 1984. Art of the Yaka and Suko. Meudon: Alain et Françoise Chaffin Editeurs.

Cantwell Smith, Wilfred. 1996. "La religión comparada: ¿a dónde y por qué?”. En Metodología de la historia de las religiones, compilado por Mircea Eliade y Joseph M. Kitagawa, 53-85. Buenos Aires: Paidós.

Colmenares, Germán. 1984. "La economía y las sociedades coloniales 1500-1800”. En Manual de historia de Colombia, vol. 1, dirigido por Jaime Jaramillo Uribe, 223-246. Bogotá: Instituto Colombiano de Cultura / Procultura.

- 1997. Historia económica y social de Colombia, vol. 2, Popayán, una sociedad esclavista, 1680-1800. Bogotá: Tercer Mundo / Fundación General de Apoyo a la Universidad del Valle / Banco de la República / Colciencias.

Del Castillo Mathieu, Nicolás. 1981. La llave de Indias. Bogotá: Ediciones El Tiempo.

Deluz, Ariane. 1975. "L'initiation d'un chamane embera”. Bulletin de la Societé Suisse des Américanistes 39: 5-11. https://www.sag-ssa.ch/bssa/pdf/bssa39_02.pdf

Eliade, Mircea. 1974. Imágenes y símbolos: ensayo sobre el simbolismo mágico religioso. Madrid: Taurus.

—. 1996. "Observaciones metodológicas sobre el estudio del simbolismo”. En Metodología de la historia de las religiones, compilado por Mircea Eliade y Joseph M. Kitagawa, 116-139. Buenos Aires: Paidós.

—. 1998. Lo sagrado y lo profano. Barcelona: Paidós.

—. 1999. Mito y realidad. Barcelona: Kairós.

—. 2000. Aspectos del mito. Barcelona: Paidós.

—. 2006. Mito y realidad. Barcelona: Kairós.

Eltis, David y David Richardson. 1997. "West Africa and transatlantic slave trade: new evidence of long-run trade”. Slavery and Abolition 18 (1): 16-35. https://doi.org/10.1080/014403 99708575201

-. 2010. Atlas of the transatlantic slave trade. New Haven; Londres: Yale University Press.

Emory University. 2019. SlaveVoyages Database v. 2.2.12. (Slaves Voyages: The Trans-Atlantic Slave Trade Database). https://www.slavevoyages.org/

Felix, Marc L. 1987. 100 People of Zaire and their sculpture: the handbook. Bruselas: Zaire Basin Art History Research Foundation.

Foss, Perkins. 2004. Where the gods and mortal meet: continuity and renewal in Urhobo art. Nueva York: Museum for African Art / Snoeck Gent. 
Friedemann, Nina S. de. 1969. "Estudios de negros en el litoral pacífico colombiano. Fase 1. Guelmanbí: formas económicas y organización social. Informe preliminar”. Revista Colombiana de Antropología 14 (1966-1969): 54-78. https://doi.org/10.22380/2539472X.1738

-. 1983. "Jaibanás neles y enfermedad: litoral pacífico". En Medicina, chamanismo y botáni$c a$, editado por Myriam Jimeno y Adolfo Triana, 27-47. Bogotá: Funcol.

—. 1984. "Estudios de negros en la antropología colombiana: presencia e invisibilidad". En Un siglo de investigación social: antropología en Colombia, editado por Jaime Arocha y Nina S. de Friedemann, 507-572. Bogotá: Etno.

-. 1989a. "Huellas de africanía en Colombia: nuevos escenarios de investigación”. Ponencia presentada en la Conferencia Internacional Persistencia Africana en el Caribe, Centro de Estudios Avanzados de Puerto Rico y el Caribe, Unesco, Instituto de Cultura Portorriqueña, Puerto Rico.

—. 1989b. Criele, criele son: del Pacífico negro. Arte, religión y cultura en el litoral pacífico. Bogotá: Planeta.

—. 1993. Presencia africana en Colombia: expedición humana. Bogotá: Pontificia Universidad Javeriana.

Friedemann, Nina S. y Jaime Arocha. 1985. Herederos del jaguar y la anaconda. Bogotá: Carlos Valencia.

—. 1986. De sol a sol: génesis, transformación y presencia de los negros en Colombia. Bogotá: Planeta.

Fuentes, Jesús J. y Armin Schwegler. 2005. Lengua y ritos de palo de monte mayombe: dioses cubanos y sus fuentes africanas. Madrid: Vervuert Iberoamericana.

Granda, Germán de. 1971. “Onomástica y procedencia africana de los esclavos negros en las minas del sur de la gobernación de Popayán (siglo XVIII)”. Revista Española de Antropología Americana 6: 381-422. https://revistas.ucm.es/index.php/REAA/article/view/REAA7171110381A/25515

—. 1988. "Los esclavos del Chocó. Su procedencia africana (siglo XVIII) y su posible incidencia lingüística en el español del área”. Thesaurus 43: 65-80. http://bibliotecadigital.caroycuervo.gov.co/681/

Hernández, Camilo A. 1995. Ideas y prácticas ambientales del pueblo embera del Chocó. Bogotá: Cerec Serie Amerindia / Colcultura.

Herskovits, Melville J. 1938. Dahomey: an ancient West African kingdom. Nueva York: Agustin.

Herskovits, Melville J. y Frances Herskovits. 1958. Dahomean narratives: a cross-cultural analysis. Evanston: Northwestern University Press.

Jiménez, Óscar. 2004. El Chocó: un paraíso del demonio. Nóvita, Citará y el Baudó, siglo XVIII. Bogotá: Universidad Nacional de Colombia / Clío.

Jurado Novoa, Fernando. 1990. La esclavitud en la costa pacífica: Iscuandé, Tumaco, Barbacoas y Esmeraldas, siglos XVI al XIX. Quito: Abya-Yala.

Kloster, William. 1998. Illicit riches: Dutch trade in the Caribbean 1648-1795. Leiden: KITLV Press. 
Lamp, Frederik. 1996. Art of the Baga: a drama of cultural reinvention. Nueva York: Museum of African Art.

Laude, Jean. 1973. Las artes del África negra. Barcelona: Labor.

Lavachery, Henri. 1954. Statuarie de l'Afrique noire (Coll. Lebègue et Nationale). Neuchâtel: La Bâconnière.

Losonczy, Anne Marie. 2006. La trama interétnica: ritual, sociedad y figuras de intercambio entre los grupos negros y embera del Chocó. Bogotá: Instituto Colombiano de Antropología e Historia / Instituto Francés de Estudios Andinos.

Lovejoy, Paul. 2012. Transformation in slavery: a history of slavery in Africa. Cambridge: Cambridge University Press.

Machado Caicedo, Martha Luz. 1996. La flor del mangle. Bogotá: Universidad de los Andes.

—. 2007. "Un rastro del África Central: el legado de los congo y angola en las tallas sagradas de los indígenas chocó del Pacífico colombiano”. En Afro-reparaciones: memorias de la esclavitud y justicia reparativa para negros, afrocolombianos y raizales, editado por Claudia Mosquera Rosero-Labbé y Luiz Claudio Barcelós, 531-555. Bogotá: Centro de Estudios Sociales / Universidad Nacional de Colombia.

-.2011. La escultura sagrada chocó en el contexto de la memoria estética de África y su diáspora: ritual y arte. Bogotá: Universidad Nacional de Colombia / Centro de Estudios Sociales; Cedla Ámsterdam; National Institute for the Study of Dutch Slavery and Its Legacy.

-. 2012. "Historia cultural en el Pacífico colombiano: el mito de origen de la medicina del pueblo indígena chocó y el legado de la diáspora africana”. En Diáspora africana: legado de resistencia y emancipación, editado por Martha Luz Machado, 255-283. Bogotá: National Institute for Study of Dutch Slavery and its Legacy; Universidad del Valle; Fundación Universitaria Claretiana.

—. 2013. "La memoria estética de África y su diáspora en Colombia en el contexto de la religiosidad del pueblo indígena chocó”. En Ensamblando heteroglosias, vol. 2 de Ensamblado en Colombia, editado por Olga Restrepo, 53-73. Bogotá: Universidad Nacional de Colombia.

Mattos, Regiane Augusto de. 2005. "A África no Brasil: grupos étnicos e organização social em São Paulo no século XIX”. Anos 9012 (21/22): 151-172. https://doi.org/10.22456/1983201X.6371

Maya, Luz Adriana. 1998. "Demografía histórica de la trata por Cartagena 1533-1810”. En Geografía humana de Colombia, vol. 6, Los afrocolombianos, editado por Adriana Maya, 9-52. Bogotá: Instituto de Cultura Hispánica.

Meza Ramírez, Carlos Andrés. 2010. Tradiciones elaboradas y modernizaciones vividas: cambio cultural en los pueblos afrochocoanos de la vía al Mar. Bogotá: Instituto Colombiano de Antropología e Historia.

Miller, Joseph. 1988. Way of death: merchant capitalism and the Angola slave trade 1730-1830. Madison: University of Wisconsin.

Mills, George. 1971. "Art: an introduction to qualitative anthropology”. En Art and aesthetic in primitive societies: a critical anthology, editado por Karol F. Jompling, 73-98. Nueva York: Dutton. 
Neyt, François. 1977. La grande statuaire hemba du Zaire. Lovaina: Institut Superieur d'Archéologie et Histoire de l'Art.

Nordenskiöld, Erland. 1929. "Les rapports entre l'art, la religion et la magie chez les indiens cuna et chocó”. Journal de la Société des Américanistes de Paris (nueva serie) 21 (1): 141-158. https://doi.org/10.3406/jsa.1929.3663

-. 1938. An historical and ethnological survey of the Cuna indians. Con la colaboración del indígena kuna Rubén Pérez Kantule, editado y corregido por Henry Wassén. Gotemburgo: Museum Etnografiska Avdelningen.

Olbrechts, Frans M. 1959. Les arts plastiques du Cong. Bruselas: Erasme.

ONIC (Organización Nacional Indígena de Colombia). S.f. “Embera Eyabida - Embera Katío”. Consultado el 17 de septiembre de 2020. https://www.onic.org.co/pueblos/1096-embera-katio

Palacios Preciado, Jorge. 1984. "La esclavitud y la sociedad esclavista”. En Manual de historia de Colombia, vol. 1, dirigido por Jaime Jaramillo Uribe, 303-343. Bogotá: Procultura.

Pardo Rojas, Mauricio. 1987. "Indígenas del Chocó”. En Introducción a la Colombia amerindia, editado por François Correa y Ximena Pachón, 251-261. Bogotá: Instituto Colombiano de Antropología.

Perrois, Louis. 1966. "Notes sur une méthode d'analyse ethno-morfologique des arts africains”. Cahiers d'Études Africaines 21: 85-99. http://www.jstor.org/stable/4390920

—. 1977. "Problèmes d'analyse de la sculpture traditionnelle du Gabon". Initiations-Documentation Techniques 32. París: Éditions de l’Office de la Recherche Scientifique et Technique d'Outre-Mer.

Phillips, Tom, ed. 1999. Africa: the art of a continent. Londres: Prestel.

Picton, John. 1995. "West Africa and Guinea Cost”. En Africa: the art of a continent, editado por Tom Phillips, 327-345. Londres: Prestel.

Pineda, Roberto y Virginia Gutiérrez. 1958. "El mundo espiritual del indio chocó”. En Miscelánea Paul Rivet, Octogenario Dicata II, XXX Congreso Internacional de Americanistas, 435-462. Ciudad de México: Universidad Nacional Autónoma de México.

—. 1984-1985. "Ciclo vital y chamanismo entre los indios chocó. Visión de mitad de siglo". Revista Colombiana de Antropología 25: 9-182. https://doi.org/10.22380/2539472X.1567

Redinha, Jose. 1962. "Um esquema evolutivo da escultura antropomorfa angolana”. Publicação de Assuntos de Interesse Ultramarino, Direção dos Serviços de Administração 173-182 (enero-septiembre): 51-56.

Reichel-Dolmatoff, Gerardo. 1953. "Algunos mitos de los indios chamí”. Revista Colombiana del Folclor 2: 148-165. https://redaprende.colombiaaprende.edu.co/metadatos/recurso/ algunos-mitos-de-los-indios-chami/

-. 1960. "Contribuciones al conocimiento de las tribus de la región del Perijá. Notas etnográficas sobre los indios chocó”. Revista Colombiana de Antropología 9: 73-158. https://doi. org/10.22380/2539472X.1589 
-. 1961. "Anthropomorphic figurines from Colombia, their magic and art". En Essays in PreColumbian art and Archaeology, de Samuel Kirkland Lothrop et al., 229-242. Cambridge: Harvard University Press.

—. 1962. "Contribuciones a la etnografía de los indios chocó”. Revista Colombiana de Antropología 11: 171-195. https://doi.org/10.22380/2539472X.1680

-. 1988. Gold work and chamanism: an iconographic study of Gold Museum. Bogotá: Banco de la República / Museo del Oro.

Robinson, J. W. L. y A. R. Bridgman. 1969. "Los indios noanama del río Taparal”. Revista Colombiana de Antropología 14 (1966-1969): 178-201. https://doi.org/10.22380/2539472X.1744

Romero, Mario Diego. 1993. Región, poblamiento y sociedad en la costa centro del Pacífico colombiano: siglo XVI al siglo XVIII. Cali: Universidad del Valle.

Santa Teresa, Severino de. 1929. "Nociones sobre creencias, usos y costumbres de los catíos del occidente de Antioquia”. Journal de la Société des Américanistes de Paris 21 (1): 71-105. https://doi.org/10.3406/jsa.1929.3658

Thornton, John. 1998. Africa and Africans in making of the Atlantic world, 1400-1800. 2. ${ }^{\mathrm{a}}$ ed. Nueva York: Cambridge University Press.

Ulloa, Astrid. 1992a. "Los emberá”. En Geografía humana de Colombia, vol. 9, Región del Pacífico, editado por Enrique Carrizosa Argáez, 94-131. Bogotá: Instituto de Cultura Hispánica.

—. 1992b. "Los grupos indígenas de los emberá”. En Geografía humana de Colombia, vol. 9, Región del Pacífico, editado por Enrique Carrizosa Argáez, 87-163. Bogotá: Instituto de Cultura Hispánica. https://babel.banrepcultural.org/digital/collection/p17054coll10/id/2752/

Vansina, Jan. 1985. Oral tradition as history. Madison: The University of Wisconsin Press.

Vargas, Patricia. 1993. "Los emberá, los waunana y los cuna. Cinco siglos de trasformaciones territoriales en la región del Chocó”. En Colombia Pacífico, vol. 2, editado por Pablo Leyva, 292-309. Bogotá: Fondo para la Protección del Medio Ambiente José Celestino Mutis.

Vasco, Luis Guillermo. 1985. Jaibanás: los verdaderos hombres. Bogotá: Biblioteca Banco Popular.

Vila Vilar, Enriqueta. 1977. Hispanoamérica y el comercio de esclavos. Sevilla: Escuela de Estudios Hispanoamericanos de Sevilla.

Wassén, Henry. 1935. "Notes on southern groups of Chocó indians in Colombia”. Etnologiska Studier 1: 35-182. https://search.proquest.com/openview/72118566db59de503a134b9529a3 69b0/1?pq-origsite=gscholar\&cbl=1817830

-. 1940. "An analogy between a South American and Oceanic myth motif and negro influence in Darien”. Etnologiska Studier 10: 69-79.

-. 1963. "Estudios chocoes. Etnohistoria chocoana y cinco cuentos waunana apuntados en 1955”. Etnografiska Studier 26: 9-78. 
—. 1988. Apuntes sobre los grupos meridionales de indígenas chocó de Colombia. Bogotá: Embajada de Suecia.

Werner Cantor, Erik. 2000. Ni aniquilados, ni vencidos: los emberá y la gente negra del Atrato bajo el dominio español, siglo XVIII. Bogotá: Instituto Colombiano de Antropología e Historia. 